\title{
Novel Approaches of Immunotherapy
}

\author{
Jeffrey R. Stokes, $M D^{\star}$ \\ Thomas B. Casale, MD
}

\section{Address}

* Division Of Allergy/Immunology, Creighton University, $601 \mathrm{~N}$ 30th St, Suite 3M-100, Omaha, NE 68131, USA

Email: jstokes@creighton.edu

Published online: 6 December 2013

(C) Springer International Publishing AG 2013

Keywords Immunotherapy · Allergy · Asthma - TLR · Allergens · Adjuvant

\section{Opinion statement}

Allergic diseases affect millions of adults and children in the United States. Allergen immunotherapy has been a treatment option for diseases such as allergic rhinitis, allergic asthma, and venom allergy for the last 100 years. In the last 25 years, alternative approaches to traditional subcutaneous immunotherapy have been developed. The purpose of these new therapies is two-fold: to improve safety and to improve the efficacy of allergen immunotherapy. Aluminum hydroxide has been used as an adjuvant to standard immunotherapy, but due to concerns about side effects, its use has been decreasing. The modification of allergens into allergoids has been an effective therapy in Europe, but at this time no preparations are available for use in the United States. Toll-like receptors have demonstrated mixed results with early trials in the United States, showing promise with the use of a TLR4 agonist, while a TLR9 agonist had disappointing results. Early studies with the use of virus-like particles with and without allergens have shown additional promise, and further trials are currently underway. These novel approaches may improve the immunologic response and often the clinical outcomes for the management of allergic diseases.

\section{Introduction}

\section{EPIDEMIOLOGY}

Allergic diseases have increased in prevalence since the 1990s, affecting up to 50 million people in the United States. Allergen immunotherapy (AIT) has been an option for treating allergic diseases since it was initially described by Noon and Freeman over 100 years ago $[1,2]$.

\section{IMMUNOTHERAPY}

Allergen immunotherapy modifies allergic diseases and subsequently reduces symptoms and medication usage. In 2007, a meta-analysis demonstrated a standardized mean difference reduction in rhinitis symptoms $(73 \%)$ and medication use (57\%) with subcutaneous immunotherapy (SCIT) [3]. In addition to allergic rhini- 
tis, multiple placebo-controlled trials have demonstrated the benefit of SCIT in treating allergic asthma and hymenoptra allergy. In fact, SCIT can be considered curative for hymenoptera allergy. SCIT has also demonstrated an ability to prevent the development of new allergen sensitization and to decrease the risk of acquiring asthma in patients with only allergic rhinitis $[4,5]$.

\section{MECHANISM}

Allergic disease is predominately a T-lymphocyte (TH2)-driven phenomenon. The mechanism of action of SCIT alters the immune response to a specific allergen from a TH2 response to a "non-allergic" T-lymphocyte (TH1) response by inducing regulatory $\mathrm{T}$ lymphocytes [6]. Regulatory T-cells downregulate allergic responses through the release of IL-10 and TGF- $\beta$. IL-10 increases the protective allergen-specific IgG4 while downregulating allergen-specific IgE. In addition, TGF- $\beta$ increases allergen-specific IgA. Subcutaneous allergen immunotherapy blunts the seasonal increase in allergen-specific IgE, while allergen-specific IgG4 production is increased.

\section{Treatment (Fig. 1)}

\section{Alum}

Alum is both a specific chemical compound and a class of chemical compounds. Aluminum salts such as aluminum hydroxide are adjuvants used in vaccines, and in AIT it is still the most widely-used [7]. Studies suggest that alums work by causing the formation of an antigen depot at the injection site where antigens are released more slowly, thereby increasing the duration of antigen interaction with the immune system, especially draining lymph nodes and antigen-presenting cells.

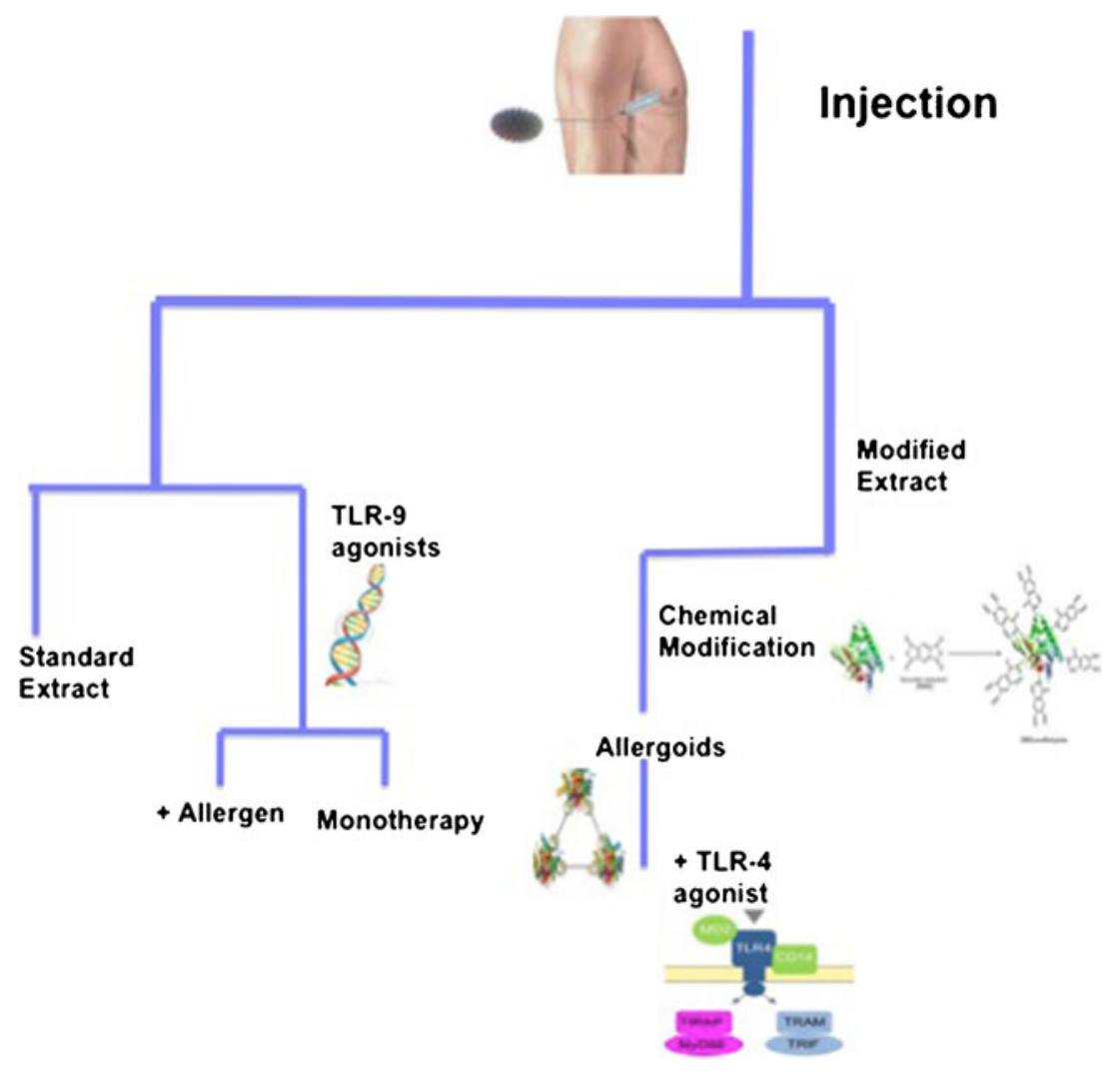

Figure 1. Alterations in immunotherapy. 
Early mouse studies suggested that alum elicited primarily a Th2 response [8]. More recent animal studies have demonstrated an increased immunogenicity and decreased allergenicity with the use of alum in AIT [9].

There is conflicting data on the potential of alum-based vaccines to increase antigen-specific IgE levels in children [10, 11]. An in vitro study on human peripheral blood mononuclear cells demonstrated that alum actually downregulates allergen-driven Th2 cytokine responses without affecting Th1 cytokines [12].

The use of alum-based grass AIT has demonstrated improvements in symptoms and reductions in medication use, but no head-to-head comparisons with non-alum-based AIT have been performed [13, 14]. While alumbased vaccines are generally well-tolerated, they may involve increased discomfort at the site of injection compared to non-alum preparations. Granulomas, though documented with alum therapy, are uncommon with subcutaneous administration [15].

\section{Allergoids}

Glutaraldehyde and formaldehyde have been used to modify allergens and produce allergoids, which reduce IgE epitopes (allergenicity) while preserving T-cell epitopes (immunogenicity) [16]. Allergoids are commonly used in European SCIT, but there are no current FDA-approved products in the United States. Depigoid ${ }^{\circledR}$ (Leti Pharma GmbH, Germany) tree pollen immunotherapy has demonstrated improvement in combined rhinoconjunctivitis symptom and medication scores compared to placebo, with $64 \%$ of patients improving with therapy [17].

Allergovit ${ }^{\circledR}$ (Allergopharma KG, Reinbek, Germany) is an aluminum hydroxide-adsorbed allergoid preparation of six-grass pollen allergens. In patients treated with pre-seasonal SCIT, treatment improved symptom scores and quality of life compared to placebo after one season [18]. In a 2-year, double-blind, placebo-controlled study in allergic rhinoconjuctivitis patients, Allergovit ${ }^{\circledR}$ reduced symptom and medication scores, increased grass-specific immunoglobulins (IgG1 and IgG4), and increased allergen tolerance by conjunctival provocation testing [19]. These improvements in medication and symptom scores and quality of life continued after a 3rd year of treatment [20]. When patients were evaluated 3 years after cessation of three seasons of treatment, their improvement in symptom scores and quality of life continued. In addition, new sensitizations were less in the allergoid-treated patients compared to those patients not treated with allergoid SCIT [21].

In the pediatric population of allergic rhinitis patients, symptomatic and inflammatory parameter improvements have also been demonstrated with Allergovit ${ }^{\circledR}$ immunotherapy. These changes include decreases in typical, seasonal grass-specific IgE rise and inhibition of the production of IL-4. After one year of immunotherapy, skin test and nasal reactivity also decreased in the actively-treated patients [22].

Acaroid $^{\circledR}$ (Allergopharma KG, Reinbek, Germany) is a dust mite allergoid combined with alum. Over 400 adult and pediatric patients tolerated cluster schedule immunotherapy with Acaroid ${ }^{\circledR}$ without significant side effects [23]. In children with allergic asthma, the use of dust 
mite allergoid SCIT improved morning peak flows while reducing inhaled corticosteroid dose compared to placebo [24•].

One concern is that the low allergenicity of allergoids in comparison to standard extracts may actually be associated with reduced immunogenicity [16]. Nonetheless, this remains a promising alternative approach to traditional SCIT, and future studies should be encouraged.

Toll-like receptors (TLRs) are innate immune receptors designed to induce TH1 and regulatory T cell responses to pathogens [25]. Endotoxins such as lipopolysaccharides (LPS) are agonists for TLR4 receptors [26]. TLR9 responds to the nucleotide sequences of unmethylated cytosine-guanine dinucleotides $(\mathrm{CpG})$, which are common in bacterial DNA. Turning on TLRs may be beneficial in preventing allergic immune responses.

Monophosphoryl lipid A (MPL $\left.{ }^{\circledR}\right)$ is a detoxified derivative of lipid A from the Salmonella Minnesota R595 lipopolysaccharide that acts as a TLR4 agonist. Pollinex ${ }^{\circledR}$ Quattro (Allergy Therapeutics, UK) is a short pollen extract allergoid adsorbed onto L-tyrosine with the addition of MPL ${ }^{\circledR}[27 \bullet]$.

An early, multicenter, placebo-controlled, randomized, double-blind clinical study in grass-allergic patients demonstrated the effectiveness of 12-grass extract Pollinex ${ }^{\circledR}$ Quattro with only four preseasonal subcutaneous injections over at least 3 weeks [28]. In patients treated with Pollinex ${ }^{\circledR}$ Quattro immunotherapy, rhinoconjunctivitis symptoms and medication use were decreased compared to placebo-treated patients. Grass-specific IgG antibody was increased with treatment, while the normal seasonal increase in grass-specific IgE was eliminated.

In a double-blind, placebo-controlled, randomized study, 14 patients received four preseasonal injections of Pollinex ${ }^{\circledR}$ Quattro birch IT $(n=9)$ or placebo $(n=5)$ [29]. Cytokine expression and proliferation of peripheral Tcell lines were evaluated before and after AIT, as well as during and after the following pollen season. Patients treated with AIT had increased IFN $\gamma$ production in vitro. Patients treated with placebo had increases in IL-4 and IL-5 production during the pollen season that were inhibited by AIT. Despite these findings, it may take two seasons of treatment for true tolerance to develop based upon allergen-specific IgG and IgG4 levels and associated increase in T-regulatory lymphocytes [30].

An open-labeled, multicenter study was performed involving 90 children and adolescents, treated with four subcutaneous injections of grass or tree Pollinex ${ }^{\circledR}$ Quattro [31]. Both grass and tree pollen treatment showed significant reductions in symptoms and medication use compared with the previous pollen seasons. In addition, after therapy, skin-prick test reactivity was significantly reduced and pollen-specific IgG was significantly increased, whereas pollen-specific IgE was unchanged.

Larger therapeutic trials were conducted in both pediatric and adult patients with allergic rhinitis, allergic conjunctivitis, and asthma caused by grasses, trees, or ragweed $[32,33]$. Skin-prick test reactions and the seasonal allergen-induced rise of IgE were significantly reduced with Pollinex ${ }^{\circledR}$ treatment, while elevating allergen-specific IgG levels [33]. In a post-marketing survey of 
over 3,000 patients given 21,428 injections over 3 years, allergic rhinitis symptoms improved in $93 \%$ of patients, and medication use decreased in $75 \%$. Local reactions occurred after $6.3 \%$ of injections, systemic reactions after $0.5 \%$ (mainly rhinitis symptoms), with no serious or anaphylactic reaction reported [34]. Similar results were seen in a pediatric population of over 400 patients with response to treatment assessed as good or very good in $94 \%$ of patients. Rescue medication use decreased from $83 \%$ to $24 \%$ after the first treatment course, and to $13 \%$ after the second course [35]. A large, randomized, double-blind, placebo-controlled study in 84 centers and with over 1,000 subjects evaluated patients with a history of allergic rhinoconjunctivitis treated with four preseason injections of Pollinex ${ }^{\circledR}$ grass IT. Treatment with grass IT improved combined symptom and medicine scores by $24 \%$ compared to placebo during peak grass season. Those patients with symptoms up to 35 years had a greater response to therapy (31\% improvement), as well as those patients in areas of high grass pollen counts or more severe disease (31\% improvement) [36].

Early trials in the United States demonstrated positive results for both grass and ragweed, but were temporarily suspended due to an adverse event. In 2012, the FDA lifted the hold in the US, and Pollinex ${ }^{\circledR}$ Quattro has now been approved to progress with a Phase III efficacy study [37]. Pollinex ${ }^{\circledR}$ Quattro is currently available for use in Austria, Germany, Greece, Italy, Portugal, Spain, and the UK.

The use of an early, phase I/IIa, double-blind, placebo-controlled study using a sublingual (SLIT) formulation of varying concentrations of grass extract with MPL was evaluated in 80 patients with allergic rhinitis out of season. Patients received daily treatments for 8 weeks. Nasal allergen challenges were performed prior to dosing and in weeks 4 and 10. All patients had positive nasal challenges at baseline. At week 10, the two groups of patients receiving the highest MPL amount demonstrated 47 and $44 \%$ negative nasal challenges compared to the grass extract-only group, with $20 \%$, and the placebo group, with $20 \%$ [38]. lergen-induced airway responses increased expression of interferon (IFN)- $\gamma$ and IFN-inducible genes [39]. Despite these changes, there was no effect on early or late allergen-induced decreases in FEV1 compared with placebo. In addition, allergen-induced sputum eosinophils and Th2-related gene expression were not altered.

ISS conjugated with an antigen was reported to be 100-fold more effective than the nonconjugated mixture in inhibiting airway eosinphils and inducing Th1 differentiation [40]. Covalently binding 4 CpG molecules to short ragweed antigen (Amb a 1) dramatically reduced allergenicity and improved immunogenicity, especially TH1 responses in humans $[41,42]$. In a mouse model of allergen-induced airway hyperresponsiveness, Amb a 1-CpG conjugate treatment reversed airway hyperresponsiveness and decreased bronchoalveolar lavage (BAL) eosinophils [43].

In vitro studies of CPG ISS in combination with Amb a 1 decreased IL-5 secretion and increased IFN- $\gamma$ production from peripheral blood mononuclear cells, reversing the ragweed-induced TH2 profile. The Amb a 1-ISS 
combination was more effective in modulating the cytokine profile than the use of ISS and Amb a 1 unlinked [44]. A subsequent in vivo study demonstrated that ragweed-induced TH2 responses were shifted toward TH1 responses, with significant increases in IFN- $\gamma$ [45]. This may be due to an increased T-regulatory cell response [46].

In an early phase, clinical study, patients with ragweed allergic rhinitis received six escalating doses of Amb a 1-immunostimulatory conjugate (AIC) (trade name Tolamba ${ }^{\mathrm{TM}}$ ) or placebo prior to ragweed season [47]. Patients treated with Tolamba ${ }^{\mathrm{TM}}$ had a significantly reduced seasonal increase in eosinophils and IL-4 mRNA-positive cells and an increased number of IFN- $\gamma$ mRNApositive cells compared with placebo-treated patients 4 to 5 months later. No symptom improvement was noted after the initial ragweed season but during the next ragweed season, Tolamba ${ }^{\mathrm{TM}}$-treated patients had fewer chest symptoms.

A double-blind, placebo controlled, phase II study with six escalating doses of AIC weekly prior to ragweed season demonstrated decreases in peak-season rhinitis symptoms and medication use during both the first and subsequent ragweed season [48]. The typical seasonally-increased Amb a 1specific IgE antibody levels were suppressed for both seasons, while a transient Amb a 1-specfic IgG increase was noted only during the first season. Immediate skin-test reactivity was decreased in the AIC-treated patients compared to placebo. In addition, the ragweed-induced TH2 cytokine profile was inhibited and IFN- $\gamma$ mRNA was increased in nasal mucosa with AIC therapy [49].

However, the development of Tolamba ${ }^{\mathrm{TM}}$ was discontinued after the interim analysis of over 700 patients in a large, multi-site trial demonstrated only minimal ragweed-induced allergic rhinitis symptoms in the placebo group. Because of this, no meaningful efficacy data could be measured. Despite this, patients from the Midwest (over half the patients) treated with placebo did have greater ragweed symptoms and the Tolamba ${ }^{\mathrm{TM}}$-treated patients had reduced total nasal-symptom scores [50].

Another therapeutic option involves using virus-like particles (VLP) to protect allergens against proteases, decrease adverse reactions and improve uptake by antigen-presenting cells. Both subcutaneous and intramuscular administration of house-dust mite (HDM) peptide inserted into a VLP (bacteriophage-derived protein Qb), markedly increased dust mite-specific IgG and IgM within 30 days of treatment [51].

A phase I/Ila study evaluated the subcutaneous injection of CpG ISS (synthetic oligodeoxynucleotide G10) contained in a bacteriophage Qb capsid (QbG10), resulting in virus-like particles,VLPs (CYT003-QbG10). This complex was admixed with HDM allergens and administered subcutaneously for 10 weeks in 20 patients with house dust mite allergy [52]. After treatment with QbG10 plus HDM, skin-test reactivity to HDM was reduced, and persisted for up to 38 weeks. The median individual increase in conjunctival HDM allergen provocation dose was 100-fold greater after therapy, with one patient demonstrating a 10,000-fold increase. Within 10 weeks of treatment, patients were nearly symptom-free and the improvement lasted for 38 weeks post-treatment. Following treatment, HDM-specific IgG increased, while 
there was a transient increase in allergen-specific IgE levels.

A larger, follow-up, phase IIb study evaluated nearly 300 patients with HDM allergy that were treated with CYT003-GbG10 without HDM allergen [53]. In patients treated with a high dose of CYT003-QbG10 as compared to those who received a placebo, rhinoconjunctivitis symptoms were significantly lower and quality of life scores were improved. The conjunctival allergen provocation test increased 10-fold in the high dose group, while in the placebo group it remained unchanged. Similar improvements were noted in patients with cat allergy [54].

In a proof-of-concept, parallel-group, double-blind, randomized trial, 63 asthmatic patients were treated with seven injections of either QbG10 (with-

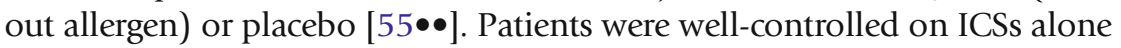
with a subsequent, controlled steroid withdrawal period to study the effect of QbG10 treatment. All patient-reported parameters (symptoms, medication use) improved overall between weeks 0 and 12 in QbG10-treated patients despite steroid withdrawal, while placebo-treated patients experienced a deterioration of symptoms. At week 12, $67 \%$ of the QbG10-treated patients were well-controlled, compared with only $33 \%$ of placebo-treated patients. FEV1 values decreased by $8 \%$ in patients who received placebo, while QbG10 patients saw no significant change $(-0.6 \%)$. Adverse events were mostly injection-site reactions (erythema, pruritis, and swelling at the injection site) occurring after QbG10 administration. A large phase III study in asthma patents is underway.

\section{Conclusion}

Allergen immunotherapy did not change dramatically in the first 75 years of its existence, but the last 25 years, and especially the last decade, have produced alternative approaches to traditional SCIT. Multiple different approaches to increase T-regulatory cells and reduce $\mathrm{TH} 2$ cytokine production are at the forefront of these changes (Table 1). Adjuvants may improve the presentation of allergens to antigen-presenting cells. The modification of the allergen chemically may make allergens more immunogenic and less allergenic. The addition of TLR agonists increases the TH1 response when added to SCIT. Finally, the use of QbG10 as a non-allergen-specific IT approach looks promising. As we find out more about the pathogenesis of allergic diseases and explore the immunologic changes induced by standard SCIT and alternative treatments, we will likely find even more ways to take advantage of that knowledge to modify allergic diseases with novel AIT approaches.

\begin{tabular}{lll}
\hline Table 1. Types of adjuvants currently used or under investigation for allergic diseases \\
\hline Treatment & Allergens & Diseases \\
Alum & Pollen & Allergic rhinitis \\
Allergoid & Pollen, Dust mite & Allergic rhinitis, asthma \\
Allergoid + Alum & Pollen, Dust mite & Allergic rhinits \\
Allergoid + TLR-4 agonist & Pollen & Allergic rhinitis \\
Immunostimulatory DNA sequences (CPG) & Ragweed & Allergic rhinitis, asthma \\
CPG + VLP & No allergen & Allergic rhinitis, asthma \\
CPG + VLP & Dust mite & Allergic rhinitis \\
\hline
\end{tabular}




\section{Compliance with Ethics Guidelines}

\section{Conflict of Interest}

Jeffrey Stokes declares that he has no conflict of interest.

Thomas Casale is a consultant to Novartis, Genentech, and Cytos and has grants/grants pending with Cytos,

Novartis, Genentech, Merck, Stallergenes, and Circassia

Human and Animal Rights and Informed Consent

This article does not contain any studies with human or animal subjects performed by any of the authors.

\section{References and Recommended Reading}

Papers of particular interest, published recently, have been highlighted as:

- Of importance

$\bullet \quad$ Of major importance

1. Noon L. Prophylactic inoculation against hay fever. Lancet. 1911;1:1572-3.

2. Freeman J. Further observations on the treatment of hay fever by hypodermic inoculations of pollen vaccine. Lancet. 1911;2:814-7.

3. Calderon MA, Alves B, Jacobson M, Hurwitz B, Sheikh A, Durham S. Allergen injection immunotherapy for seasonal allergic rhinitis. Cochrane Database Syst Rev. 2007 Jan 24;(1):CD001936. Review.

4. Des Roches A, Paradis L, Menardo JL, Bouges S, Daures JP, Bousquet J. Immunotherapy with a standardized Dermatophagoides pteronyssinus extract. VI. Specific immunotherapy prevents the onset of new sensitizations in children. J Allergy Clin Immunol. 1997;99:450-3.

5. Möller C, Dreborg S, Ferdousi HA, Halken S, Høst A, Jacobsen L, et al. Pollen immunotherapy re- duces the development of asthma in children with seasonal rhinoconjunctivitis (the PAT-study). J Allergy Clin Immunol. 2002;109:251-6.

6. James LK, Durham SR. Update on mechanisms of allergen injection immunotherapy. Clin Exp Allergy. 2008;38:1074-88.

7. Sledge RF. Treatment of hay-fever with alum-precipitated pollen. US Naval Med Bull. 1938;36:18.

8. Comoy EE, Capron A, Thyphronitis G. In vivo induction of type 1 and 2 immune responses against protein antigens. Int Immunol. 1997;9(4):523-31.

9. Rask C, Lund L, Lund G, Heydenreich B, Wurtzen P, Bellinghausen I, et al. An alternative allergen:adjuvant formulation potentiates the immunogenicity and reduces allergenicity of a novel subcutaneous immunotherapy product for treatment of grass-pollen allergy. Clin Exp Allergy.
2012;42(9):1356-68. doi:10.1111/j.13652222.2012.04026.x.

10. Mark A, Björkstén B, Granström M. Immunoglobulin E responses to diphtheria and tetanus toxoids after booster with aluminium-adsorbed and fluid DTvaccines. Vaccine. 1995;13(7):669-73.

11. Duchén $K$, Granström $M$, Hedenskog S, Blennow $M$, Björkstén B. Immunoglobulin $\mathrm{E}$ and $\mathrm{G}$ responses to pertussis toxin in children immunised with adsorbed and non-adsorbed whole cell pertussis vaccines. Vaccine. 1997;15(14):1558-61.

12. Wilcock LK, Francis JN, Durham SR. Aluminium hydroxide down-regulates $\mathrm{T}$ helper 2 responses by allergen-stimulated human peripheral blood mononuclear cells. Clin Exp Allergy. 2004;34(9):1373-8.

13. Powell RJ, Frew AJ, Corrigan CJ, Durham SR. Effect of grass pollen immunotherapy with Alutard SQ on quality of life in seasonal allergic rhinoconjunctivitis. Allergy. 2007;62(11):1335-8.

14. Frew AJ, Powell RJ, Corrigan CJ, Durham SR, UK Immunotherapy Study Group. Efficacy and safety of specific immunotherapy with SQ allergen extract in treatment-resistant seasonal allergic rhinoconjunctivitis. J Allergy Clin Immunol. 2006;117(2):319-25.

15. Vogelbruch M, Nuss B, Korner M, Kapp A, Kiehl P, Bohm W. Aluminium-induced granulomas after inaccurate intradermal hyposensitization injections of aluminium-adsorbed depot preparations. Allergy. 2000;55(9):883-7.

16. Henmar H, Lund G, Lund L, Petersen A, Würtzen PA. Allergenicity, immunogenicity and dose-relationship of three intact allergen vaccines and four allergoid vaccines for subcutaneous grass pollen immunotherapy. Clin Exp Immunol. 2008;153:316-23. 
17. Pfaar O, Robinson DS, Sager A, Emuzyte R. Immunotherapy with depigmented-polymerized mixed tree pollen extract: a clinical trial and responder analysis. Allergy. 2010. doi:10.1111/j.13989995.2010.02413.x.

18. Rajakulasingam K. Early improvement of patients' condition during allergen-specific subcutaneous immunotherapy with a high-dose hypoallergenic 6grass pollen preparation. Eur Ann Allergy Clin Immunol. 2012;44(3):128-34.

19. Corrigan CJ, Kettner J, Doemer C, Cromwell O, Narkus A, Study Group. Efficacy and safety of preseasonal-specific immunotherapy with an aluminium-adsorbed six-grass pollen allergoid. Allergy. 2005;60:801-7.

20. Williams A, Henzgen M, Rajakulasingam K. Additional benefit of a third year of specific grass pollen allergoid immunotherapy in patients with seasonal allergic rhinitis. Eur Ann Allergy Clin Immunol. 2007;39:123-6.

21. Dominicus R. 3-years' long-term effect of subcutaneous immunotherapy (SCIT) with a high-dose hypoallergenic 6-grass pollen preparation in adults. Eur Ann Allergy Clin Immunol. 2012 Jun 44(3):135-40.

22. Keskin O, Tuncer A, Adalioglu G, Sekerel BE, Saçkesen C, Kalayci O. The effects of grass pollen allergoid immunotherapy on clinical and immunological parameters in children with allergic rhinitis. Pediatr Allergy Immunol. 2006;17(6):396-407.

23. Nieto García A, Nevot Falcó S, Carrillo Díaz T, Cumplido Bonny JA, Izquierdo Calderón JP, Hernández-Peña J. Safety of cluster specific immunotherapy with a modified high-dose house dust mite extract. Eur Ann Allergy Clin Immunol. 2013;45(3):78-83.

24. Zielen S, Kardos P, Madonini E. Steroid-sparing effects with allergen-specific immunotherapy in children with asthma: A randomized controlled trial. J Allergy Clin Immunol. 2010;126(5):942-9.

doi:10.1016/j.jaci.2010.06.002.

This study demonstrates the benefit of immunotherapy on asthma in children. The use of allergoid SCIT improved lung function and decreased ICS use, modifying the asthma disease state.

25. Racila DM, Kline JN. Perspectives in asthma: molecular use of microbial products in asthma prevention and treatment. J Allergy Clin Immunol.

2005;116:1202-5.

26. Tulic MK, Fiset PO, Manoukian JJ, Frenkiel S, Lavigne F, Eidelman DH, et al. Role of toll-like receptor 4 in protection by bacterial lipopolysaccharide in the nasal mucosa of atopic children but not adults. Lancet. 2004;363:1689-97.

27. Rosewich M, Lee D, Zielen S. Pollinex Quattro: An innovative four injections immunotherapy In allergic rhinitis. Hum Vaccin Immunother. 2013 Apr 12;9(7) This article summarizes all the data associated with
Pollinex ${ }^{\circledR}$ Quattro immunotherapy including mechanisms.

28. Drachenberg KJ, Wheeler AW, Stuebner P, Horak F. A well-tolerated grass pollen-specific allergy vaccine containing a novel adjuvant, monophosphoryl lipid A, reduces allergic symptoms after only four preseasonal injections. Allergy. 2001;56:498-505.

29. Boris A. Stuck, Solange Schneider-Gene, Dirk Schafer, Ludger Klimek and Karl Harmann Short-term preseasonal immunotherapy with birch pollen allergoid plus monophosphoryl lipid $A\left(\mathrm{MPL}^{\circledR}\right)$ : influence on cytokine production of peripheral T-cells in patients with allergic rhinitis. Allergy Clin Immunol Int - J World Allergy Org. 2004;16:60-4.

30. Rosewich M, Schulze J, Eickmeier O, Telles T, Rose MA, Schubert R, et al. Tolerance induction after specific immunotherapy with pollen allergoids adjuvanted by monophosphoryl lipid A in children. Clin Exp Immunol. 2010;160(3):403-10. doi:10.1111/j.1365-2249.2010.04106.x..

31. Drachenberg KJ, Heinzkill M, Urban E, Woroniecki SR. Efficacy and tolerability of short-term specific immunotherapy with pollen allergoids adjuvanted by monophosphoryl lipid A (MPL) for children and adolescents. Allergol Immunopathol (Madr). 2003;31:270-7.

32. Gawchik SM, Saccar CL. Pollinex Quattro Tree: allergy vaccine. Expert Opin Biol Ther. 2009;9:377-82.

33. McCormack PL, Wagstaff AJ. Ultra-short-course seasonal allergy vaccine (Pollinex Quattro). Drugs. 2006;66:931-8.

34. Zielen S, Metz D, Sommer E, Scherf HP. Short-term immunotherapy with allergoids and the adjuvant monophosphoryl lipid a. Results from a 3-year postmarketing surveillance study. Allergologie. 2007;30:S1-9.

35. Rosewich M, Schulze J, Fischer von WeikersthalDrachenberg KJ, Zielen S. Ultra-short course immunotherapy in children and adolescents during a 3-yrs post-marketing surveillance study. Pediatr Allergy Immunol. 2010;21:e185-9.

36. DuBuske LM, Frew AJ, Horak F, Keith PK, Corrigan CJ, Aberer W, et al. Ultrashort-specific immunotherapy successfully treats seasonal allergic rhinoconjunctivitis to grass pollen. Allergy Asthma Proc. 2011;32(3):239-47. doi:10.2500/ aap.2011.32.3453.

37. http://www.allergytherapeutics.com/fda-clinical-holdlifted-phase\%20III-agreed.aspx accessed 8/15/13

38. Allergy Therapeutics. FDA Clinical Hold Lifted. August 3, 2012. http://www.allergytherapeutics.com/ fda-clinical-hold-lifted-phase\%20III-agreed.aspx accessed 8/15/13

39. Gauvreau GM, Hessel EM, Boulet LP, Coffman RL, O'Byrne PM. Immunostimulatory sequences regulate interferon-inducible genes but not allergic airway 
responses. Am J Respir Crit Care Med. 2006;174(1):15-20.

40. Shirota H, Sano K, Kikuchi T, Tamura G, Shirato K. Regulation of murine airway eosinophilia and Th2 cells by antigen-conjugated CpG oligodeoxynucleotides as a novel antigen-specific immunomodulator. J Immunol. 2000;164(11):5575-82.

41. Tighe H, Takabayashi K, Schwartz D, Van Nest G, Tuck S, Eiden JJ, et al. Conjugation of immunostimulatory DNA to the short ragweed allergen amb a 1 enhances its immunogenicity and reduces its allergenicity. J Allergy Clin Immunol. 2000;106:124-34.

42. Higgins D, Rodriguez R, Milley R, Marshall J, Abbate $\mathrm{C}$, dela Cruz T, et al. Modulation of immunogenicity and allergenicity by controlling the number of immunostimulatory oligonucleotides linked to Amb a 1. J Allergy Clin Immunol. 2006;118:504-10.

43. Santeliz JV, Van Nest G, Traquina P, Larsen E, WillsKarp M. Amb a 1-linked CpG oligodeoxynucleotides reverse established airway hyperresponsiveness in a murine model of asthma. J Allergy Clin Immunol. 2002;109(3):455-62.

44. Marshall JD, Abtahi S, Eiden JJ, Tuck S, Milley R, Haycock F, et al. Immunostimulatory sequence DNA linked to the Amb a 1 allergen promotes $\mathrm{T}(\mathrm{H}) 1 \mathrm{cy}$ tokine expression while downregulating $\mathrm{T}(\mathrm{H}) 2 \mathrm{cy}-$ tokine expression in PBMCs from human patients with ragweed allergy. J Allergy Clin Immunol. 2001;108:191-7.

45. Simons FE, Shikishima Y, Van Nest G, Eiden JJ, HayGlass KT. Selective immune redirection in humans with ragweed allergy by injecting Amb a 1 linked to immunostimulatory DNA. J Allergy Clin Immunol. 2004;113:1144-51.

46. Asai K, Foley SC, Sumi Y, Yamauchi Y, Takeda N, Desrosiers $\mathrm{M}$, et al. Amb a 1-immunostimulatory oligodeoxynucleotide conjugate immunotherapy increases CD4+CD25+ T cells in the nasal mucosa of subjects with allergic rhinitis. Allergol Int. 2008;57(4):377-81. doi:10.2332/allergolint.O-07-528.

47. Tulic MK, Fiset PO, Christodoulopoulos $\mathrm{P}$, Vaillancourt P, Desrosiers M, Lavigne F, et al. Amb a 1-immunostimulatory oligodeoxynucleotide conjugate immunotherapy decreases the nasal inflamma- tory response. J Allergy Clin Immunol. 2004;113:235-41.

48. Creticos PS, Schroeder JT, Hamilton RG, BalcerWhaley SL, Khattignavong AP, Lindblad R, et al. Immune Tolerance Network Group. Immunotherapy with a ragweed-toll-like receptor 9 agonist vaccine for allergic rhinitis. N Engl J Med. 2006;355:1445-55.

49. Tulic $\mathrm{MK}$, Christodoulopoulos $\mathrm{P}$, Fiset $\mathrm{PO}$, Vaillancourt P, Lavigne F, Marshall JD, et al. Local induction of a specific Th1 immune response by allergen linked immunostimulatory DNA in the nasal explants of ragweed-allergic subjects. Allergol Int. 2009;58:565-72.

50. Dynavax Reports Interim TOLAMBA TM Ragweed Allergy Results from DARTT Trial press release. http:// investors.dynavax.com/releasedetail.cfm?releaseid= 230979 accessed 8/15/13

51. Kündig TM, Senti G, Schnetzler G, Wolf C, Prinz Vavricka BM, Fulurija A, et al. Der p 1 peptide on virus-like particles is safe and highly immunogenic in healthy adults. J Allergy Clin Immunol. 2006;117:1470-6.

52. Senti G, Johansen P, Haug S, Bull C, Gottschaller C, Müller $\mathrm{P}$, et al. Use of A-type CpG oligodeoxynucleotides as an adjuvant in allergenspecific immunotherapy in humans: a phase I/IIa clinical trial. Clin Exp Allergy. 2009;39:562-70.

53. Klimek L, Willers J, Hammann-Haenni A, Pfaar O, Stocker H, Mueller P, Renner WA, Bachmann MF. Assessment of clinical efficacy of CYT003-QbG10 in patients with allergic rhinoconjunctivitis: a phase IIb study. Clin Exp Allergy. 2011;41(9):1305-12. doi:10.1111/j.1365-2222.2011.03783.x.

54. Blaziene A, Leisyte P, Sitkauskiene B, Kits L, Savisaar M, Lozovskis V, et al. CYT003-QbG10, A Novel Allergen-independent Immunotherapy, Shown to be Safe and Efficacious in Placebo-controlled Phase II Study. Ann Allergy Asthma Immunol. 2009;102:Sa8.

55.• Beeh KM, Kanniess F, Wagner F, Schilder C, Naudts I, Hammann-Haenni A, et al. The novel TLR-9 agonist QbG10 shows clinical efficacy in persistent allergic asthma. J Allergy Clin Immunol. 2013;131(3):86674. doi:10.1016/j.jaci.2012.12.1561.

This study demonstrates the effectiveness of just the adjuvant without any specific allergen on reducing ICS dose on asthma patients on moderate and high-dose ICS. Patients had symptom improvement even with the decrease of ICS. 